\title{
The Allergic Airway Inflammation Repository - a user-friendly, curated resource of mRNA expression levels in studies of allergic airways
}

\author{
Danuta Gawel, A. Rani James, Mikael Benson, R. Liljenstrom, A. Muraro, Colm Nestor, \\ Huan Zhang and Mika Gustafsson
}

\section{Linköping University Post Print}

\section{Tweet}

N.B.: When citing this work, cite the original article.

Original Publication:

Danuta Gawel, A. Rani James, Mikael Benson, R. Liljenstrom, A. Muraro, Colm Nestor, Huan Zhang and Mika Gustafsson, The Allergic Airway Inflammation Repository - a user-friendly, curated resource of mRNA expression levels in studies of allergic airways, 2014, Allergy. European Journal of Allergy and Clinical Immunology, (69), 8, 1115-1117.

http://dx.doi.org/10.1111/all.12432

Copyright: Wiley

http://eu.wiley.com/WileyCDA/

Postprint available at: Linköping University Electronic Press http://urn.kb.se/resolve?urn=urn:nbn:se:liu:diva-109581 
The Allergic Airway Inflammation Repository - a user-friendly, curated resource of mRNA expression levels in studies of allergic airways.

Danuta Gawel ${ }^{a^{*}}$, Alva Rani James ${ }^{a^{*},}$ Mikael Benson ${ }^{\mathrm{a}}$, Robert Liljenströmª, Antonella Muraro ${ }^{\mathrm{b}}$, Colm E. Nestor ${ }^{a}$, Huan Zhang ${ }^{a *}$, Mika Gustafsson $^{\text {a* }}$

${ }^{a}$ Centre for Individualised Medicine, Department of Clinical and Experimental Medicine, Linköping University, Linköping, Sweden

${ }^{b}$ Referral Centre for Food Allergy Diagnosis and Treatment, Veneto Region, Department of Women and Child Health, Padua University Hospital, Padua, Italy

*These authors contributed equally to the paper and serve as joint first and last authors.

\section{Corresponding author}

Mika Gustafsson, PhD

The Centre for Individualised Medicine

Linköping University Hospital

58185 Linköping

Sweden

Telephone: +46 72-227 6505

E-mail: mika.gustafsson@liu.se

Authors' contributions: D.G designed research, acquired and analysed data, and wrote the paper; M.B. designed research and wrote the paper, R.L. designed research and wrote the paper; A.M. acquired data; C.E.N designed research and wrote the paper; A.R.J. designed research, developed the database and website, and wrote the paper; H.Z designed research; M.G. designed research and acquired data.

Declaration of all sources of funding: This work was supported by the Swedish Research Council.

Disclosure of potential conflict of interest: The authors declare that they have many conflicts, but none of interest.

Short title: Allergic Airway Inflammation Repository

Key words: Allergy, mRNA microarray, repository

Word count: 744 without title page, abstract, references and figure legend 


\begin{abstract}
Public microarray databases allow analysis of expression levels of candidate genes in different contexts. However, finding relevant microarray data is complicated by the large number of available studies. We have compiled a user-friendly, open access database of mRNA microarray experiments relevant to allergic airway inflammation, the Allergic Airway Inflammation Repository ( $\underline{A A I R}$, http://aair.cimed.ike.liu.se/). The aim is to allow allergy researchers to determine the expression profile of their genes of interest in multiple clinical data sets and several experimental systems quickly and intuitively. AAIR also provides quick links to other relevant information such as experimental protocols, related literature, and raw data files.
\end{abstract}


High-throughput data stored in public databases like the gene expression omnibus (GEO, http://www.ncbi.nlm.nih.gov/geo/) and ArrayExpress (http://www.ebi.ac.uk/arrayexpress) constitute formidable resources for researchers. Given the explosion of high-throughput data generation over the last decade, these repositories have grown exponentially in size. Currently, GEO contains more than 150,000 mRNA microarray studies alone, as well as several other forms of high-throughput data. Because scientific journals require that high throughput data from publications are stored in public databases, these grow at very high rates (1). The relevance to allergy researchers lies in that such databases can be used for a range of different in silico experiments. For example, to find the expression levels of IL4 in experiments relevant to allergy, this gene and a given cell type or experimental context can be searched for. This will generate a list of multiple different experiments, which can be further explored to find the expression profiles of the gene as well as information about experimental conditions and a reference to the publication. It is also possible to identify co-expressed genes, which may help to identify novel, functionally related candidate genes which can be subsequently linked to data in other external databases such as Online Mendelian Inheritance in Man (OMIM) and Medline. Advanced searches can also be made and combined with a large number of other constantly developing databases, such as OMIM or Medline. It is, in fact, possible to perform research solely based on datasets from different databases, to generate and test hypotheses completely in silico $(2,3)$. These possibilities and developments suggest that increased use of public high-throughput databases is a valuable complement to allergy research. Ideally, such database searches should be part of the routine experimental design and validation, similar to making a literature search. However, the scale and complexity of many repositories often acts as a barrier to their use by basic researchers. For example, finding relevant experiments among the 150,000 available datasets may involve making multiple searches across different cell types, diseases or experimental conditions, as well as individual assessments of the relevance of each study which can be both time-consuming and technically challenging.

To make this valuable data more accessible to allergy researchers, we have constructed an independent, open access database of allergy-relevant datasets from studies related to allergic airway inflammation, with an intuitive, user-friendly interface: the Allergic Airway Inflammation Repository (AAIR, http://aair.cimed.ike.liu.se/).

The database provides the user with information on the expression values of userdefined genes in a given study and under given experimental conditions, as well as statistical components such as mean and median values, fold change, and $p$-values from comparisons between the different experimental conditions in the selected studies. It can also provide a list of the associated probes with a given gene, ranked by $p$-values of comparisons over different experimental conditions, in order to easily determine under which experimental conditions a given gene is differentially expressed.

The Allergic Airway Inflammation Repository includes a short introduction of its content and how to use it, as well as links to 1 ) a list of selected datasets relevant to allergic 
airway inflammation, 2) a large scale repository for comprehensive searches, 3) a database that contains information about mRNA expression levels in different cell types and tissues, as well as summary information about gene function (http://biogps.org).

The selected data sets include data from studies on allergic airway inflammation induced by allergens as well as microbes. These studies have been performed on CD4 + and CD8 + T cells, PBMC and epithelial cells from different levels of the respiratory tract (3-13). The database also includes a study of monozygotic twins, discordant for seasonal allergic rhinitis (14). Microarray data of RNA expression levels in different T cell subsets have also been included (15).

The repository can be used either to 1) search for the expression levels of a gene of interest in an individual study, or 2) obtain a summary table of fold change ratio over mean expression levels in different study groups, together with $p$-values for the difference (Figure 1). Importantly, the database also provides a detailed description of the experimental protocol used in each study and simple links to the articles related to each study and the raw data for download.

For detailed information of our methods and statistical analyses, we refer to the supplementary document 1: methods.

In summary, we have constructed a user-friendly microarray repository relevant to allergic airway inflammation. We hope this will serve as a valuable complement to large scale databases, and also increase the use of them. 


\section{References}

1. Wilhite SE, Barrett T. Strategies to explore functional genomics data sets in NCBI's GEO database. Methods in molecular biology 2012;802:41-53.

2. Pedicini M, Barrenas F, Clancy T, Castiglione F, Hovig E, Kanduri K, et al. Combining network modeling and gene expression microarray analysis to explore the dynamics of Th1 and Th2 cell regulation. PLoS computational biology 2010;6(12):e1001032.

3. Barrenas F, Chavali S, Alves AC, Coin L, Jarvelin MR, Jornsten R, et al. Highly interconnected genes in disease-specific networks are enriched for disease-associated polymorphisms. Genome biology 2012;13(6):R46.

4. Nestor CE, Barrenas F, Wang H, Lentini A, Zhang H, Bruhn S, et al. DNA methylation changes separate allergic patients from healthy controls and may reflect altered $\mathrm{CD} 4+\mathrm{T}$-cell population structure. PLoS genetics 2014;10(1):e1004059.

5. Wagener AH, Zwinderman AH, Luiten S, Fokkens WJ, Bel EH, Sterk PJ, et al. dsRNAinduced changes in gene expression profiles of primary nasal and bronchial epithelial cells from patients with asthma, rhinitis and controls. Respiratory research 2014;15(1):9.

6. Aguerri M, Calzada D, Montaner D, Mata M, Florido F, Quiralte J, et al. Differential gene-expression analysis defines a molecular pattern related to olive pollen allergy. Journal of biological regulators and homeostatic agents 2013;27(2):337-350.

7. Wagener AH, Zwinderman AH, Luiten S, Fokkens WJ, Bel EH, Sterk PJ, et al. The impact of allergic rhinitis and asthma on human nasal and bronchial epithelial gene expression. PloS one 2013;8(11):e80257.

8. Giovannini-Chami L, Marcet B, Moreilhon C, Chevalier B, Illie MI, Lebrigand K, et al. Distinct epithelial gene expression phenotypes in childhood respiratory allergy. The European respiratory journal 2012;39(5):1197-1205.

9. Bosco A, McKenna KL, Firth MJ, Sly PD, Holt PG. A network modeling approach to analysis of the Th2 memory responses underlying human atopic disease. Journal of immunology 2009;182(10):6011-6021.

10. Kicic A, Hallstrand TS, Sutanto EN, Stevens PT, Kobor MS, Taplin C, et al. Decreased fibronectin production significantly contributes to dysregulated repair of asthmatic epithelium. American journal of respiratory and critical care medicine 2010;181(9):889-898.

11. Chamberland A, Madore AM, Tremblay K, Laviolette M, Laprise C. A comparison of two sets of microarray experiments to define allergic asthma expression pattern. Experimental lung research 2009;35(5):399-410.

12. Vroling AB, Jonker MJ, Luiten S, Breit TM, Fokkens WJ, van Drunen CM. Primary nasal epithelium exposed to house dust mite extract shows activated expression in allergic individuals. American journal of respiratory cell and molecular biology 2008;38(3):293-299.

13. Tsitsiou E, Williams AE, Moschos SA, Patel K, Rossios C, Jiang X, et al. Transcriptome analysis shows activation of circulating CD8+ T cells in patients with severe asthma. The Journal of allergy and clinical immunology 2012;129(1):95-103.

14. Sjogren AK, Barrenas F, Muraro A, Gustafsson M, Saetrom P, Wang H, et al. Monozygotic twins discordant for intermittent allergic rhinitis differ in mRNA and protein levels. Allergy 2012;67(6):831-833.

15. Zhang $\mathrm{H}$, Nestor $\mathrm{CE}$, Zhao $\mathrm{S}$, Lentini $\mathrm{A}$, Bohle $\mathrm{B}$, Benson $\mathrm{M}$, et al. Profiling of human CD4+ T-cell subsets identifies the TH2-specific noncoding RNA GATA3-AS1. The Journal of allergy and clinical immunology 2013;132(4):1005-1008. 


\section{Home}

\section{Expression Analysis}

Enter Search Key

\section{GATA3}

Select Search Type

gene_name

Select Study

\section{CD4/CD8 in severe and non-severe asthma}

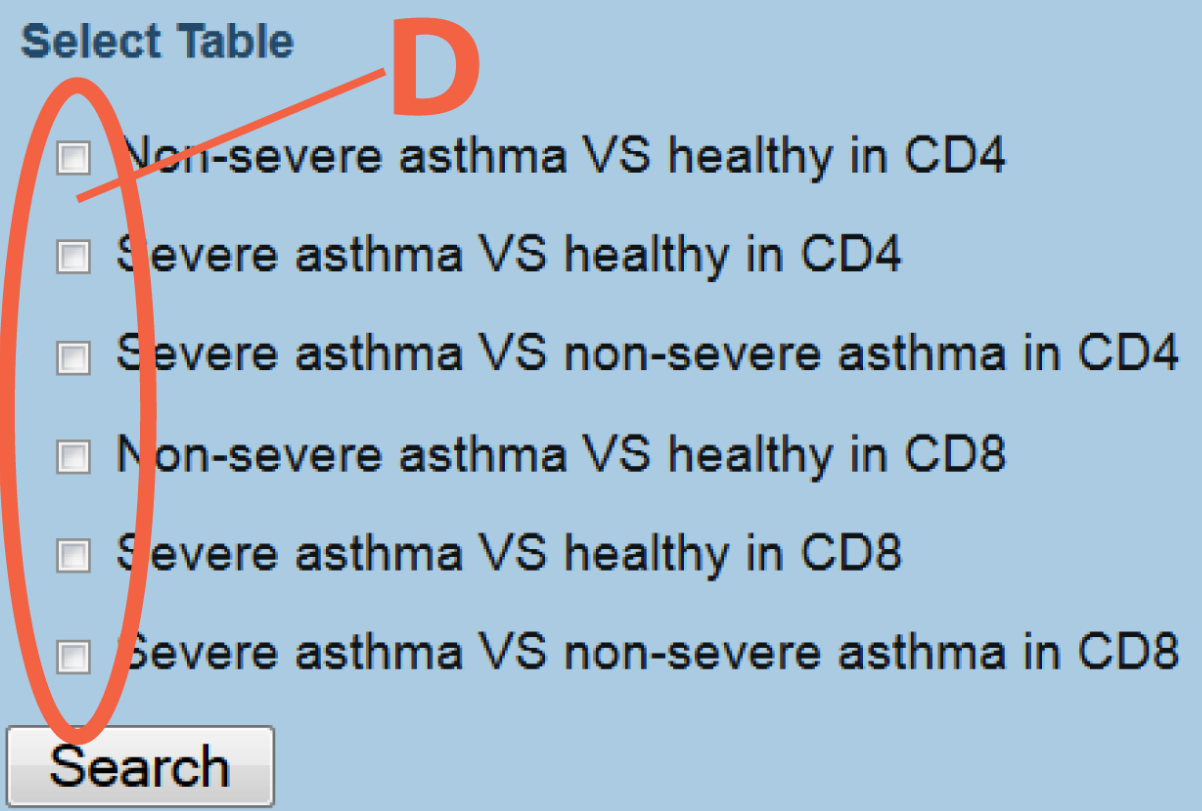

\section{Gene Search}

Enter Gene Name

Search Gene 